\title{
Low food quality hinders male height growth more than female's in Burkina Faso
}

\author{
Bernard DEMBELE ${ }^{1, *}$, Mouftaou AMADOU SANNI ${ }^{2}$ \\ ${ }^{1}$ Msc in Demography, Research assistant, Laboratory of Research in Sciences of Population \\ and Development, University of Parakou, Benin
}

${ }^{2}$ Professor titular in Demography, Director of Laboratory of Research in Sciences of Population and Development, University of Parakou, Benin

*Corresponding author: dembele_b@yahoo.com

\section{ABSTRACT}

As in many developing countries, stunting is a public health problem in Burkina Faso. More than one in four children does not reach his or her growth potential. In addition, all nutrition surveys conducted in the country reveal that boys are more affected. This stunting gender bias is supported by the Trivers-Willard theory that there is a natural discriminating investment in reproduction according to sex through sociodemographic characteristics, behaviour and biology. The present study is intended to investigate the role of food quality in the occurrence of this phenomenon.

This cross-sectional and explanatory study of children under five years of age is based on data from Burkina Faso's latest 2010 Demographic and Health Survey. Analyses were carried out on only the subsample of 6994 under-five year old children on which the anthropometric measures were taken. The assessment of child growth is based on the anthropometric index height-for-age z-score and the food quality assessment is based on the joint WHO/Unicef standard. The explanatory model used to examine the effect of the food quality is based on logistic regression. The prevalence of balanced diets among the children was $7.2 \%$ and there was no gender difference. On the other hand, stunting prevalence was significantly higher for boys $(37.7 \%$ versus $32.6 \%$ ). Children who were subjected to suboptimal feeding practices had three times more adjusted risk of stunting for both sexes. In addition, poor feeding practices led to a significantly higher growth deficit in boys compared to girls. However, when the diet was adequate, this risk gap dwindled. The higher prevalence of stunting of boys in the absence of food discrimination led us to single out behaviour and biology effects as the likely explanatory variables. Girls' natural resilience to certain infections and nutritional deficiencies could explain this difference in risk. Improved under-five year old child feeding practices contribute to improving overall growth stature and contribute also to bridging the gender gap in stunting.

Key-words: Feeding practice, Stunting, Gender, Child, Burkina-Faso 


\section{INTRODUCTION}

Child stunting is a public health problem in Burkina Faso. Stunting prevalence decreased from 35.1\% in 2009 to 29.1\% in 2014 (DN et Unicef 2009)(DN et Unicef 2014). Despite the decline, these levels are high according to WHO (OMS 1995). It is imperative to combat this form of malnutrition because of its harmful consequences. These potential impacts are multiple and varied from cognitive developmental retardation, poor academic performance, anxiety, depression, impaired self-esteem, antisocial behaviours, impulsivity, hyperactivity to decreased attention (Caulfield et al. 2006)(Susan P. Walker et al. 2007)(Chang et al. 2002)(S. P. Walker et al. 2011). Stunting may also lead to chronic diseases in adulthood (hypertension, diabetes, obesity and cardiovascular disease) according to the developmental origin of health and diseases theory (Forouzanfar et al. 2016)(Calkins et Devaskar 2011). In addition, a 10\% increase in GNP is associated with a reduction in the prevalence of stunting of 0.7 to 2.2 points (Heltberg 2009)(Bershteyn et al. 2015) .

As in many countries in sub-Saharan Africa, boys in Burkina Faso are more vulnerable to nutritional stunting. National nutritional surveys carried out in the country found significant differences between girls and boys. In 2014, prevalence was $26.1 \%$ for girls and $31.0 \%$ for boys. In 2013, these values were $29.0 \%$ and $34.0 \%$ respectively. Similarly, in 2009 there were 32.0\% and 37.0\% respectively (DN and Unicef 2009)(DN and Unicef 2014). Thus, although levels are declining, gender gaps have persisted over time. To explain this situation, Kennedy and Bentley (1994) downplayed the possible role of biology, and rather invoked behaviour and culture. However, Wamani et al. (2007) and Condo et al. (2015) suggest not just behaviours, but also biological aspects. (Muenchhoff and Goulder 2014) agreed on some reasons such as gender differences in immunity and behaviour between the boy and girl. On the other hand, (Wondimagegn 2014) expands the field by encompassing biological, behavioural and sociocultural mechanisms altogether.

The proximal determinants of a child's stunting are food consumption and all other factors that contribute to overall health (Ndiku et al. 2011). However, food quality is given a special priority, since stunting is highly sensitive to food consumption in quantity and quality (Dewey et Begum 2011). In many contexts, inadequate feeding practices over a long period of time are the predominant factor in the deterioration of the nutritional status of under-five years old children (Wondimagegn 2014).

This article aims at understanding the role of inadequate feeding in the higher prevalence of stunting phenomenon in Burkina Faso. The study first synthesizes knowledge on gender differences in stunting, then reviews the method elements, the dataset used, variables, analysis procedures, and then reach the discussion that identifies perspective of further reflexions.

\section{METHODS}

\section{Description of variables}

The dependent variable (stunting) is based on the height-for-age z-score index (WHO 2006 standard) using height, age and sex data. The calculations were made by the software WHOAnthro version 3.2.2. On this basis, a child is considered as stunted if the height-for-age z-score is lower than -2 (OMS 1995). In general, this index provides information on long-term nutritional status. 
As suggested by Wondimagegn (2014), the independent factors in the present study have been assembled into three main groups. First, socio-demographic and cultural factors encompass sex, age (in months) of the child, marital status, religion, formal education level, the mother's ethnicity (grouped into Mossi, Gurmantche, Fulani, Senufo, and other), the assets owned and living conditions according to Filmer et Pritchett (1998) to obtain three items (poor, medium and well-off). Second, behavioural factors consisted of hygiene (synthesized from waste management, waste water, hand washing, toilet, kitchen and drinking water source), number of children. Third, biological factors encompass the child's birth size, diarrhoea in the last two weeks preceding the interview and the birth interval. These also include the mother's body mass index, which is the ratio of weight to square height $(\mathrm{kg} / \mathrm{m} 2)$ that determines the nutritional status defined into three categories ((Malnourished $(<18.5)$, Normal $(18.5-25)$ and Overweight/obese (>25)), age, height of mother and her pregnancy status.

Child food consumption assessment is based on a 24-hour recall using the WHO/Unicef approach (OMS et al. 2011). It comprises the practice of EBF for up to 6 months, the adequacy of the complementary food received between 6-8 months, and the diversity of food intake, along with the continuation of breastfeeding from 9-23 months. These recommendations were made by WHO in 2003 and are considered to contribute to optimal infant and young child nutrition (IYCN), normal development and balanced growth (WHO 2003).

Exclusive breastfeeding (EBF) is defined as the practice of feeding a new-born only with breast milk, including prescribed medications. Water, breast milk substitutes, herbal teas, other liquids and solid foods are excluded (WHO 2003). EBF in the first six months of life is recognized to improve the growth, health and survival of the new-born (Agho et al. 2011). After age of 6 months, breast milk alone becomes insufficient to meet micro and macro-nutrient needs of infant normal growth (Cousens et al. 1993). Then complementary food becomes necessary to achieve good health and reduce malnutrition risk. The risk increases significantly when food is only introduced after 12 months (AOR=2.2) (Teshome et al. 2009).

The recommendation of continuing breastfeeding for at least two years was first presented in the Innocenti Declaration jointly elaborated by WHO and Unicef along with over 40 participating governments in 1990. The main reason invoked is that breast milk beyond one year is a significant source of vitamin A, calcium and protein and a means of infection prevention (Delgado et Matijasevich 2013). Prolonged breastfeeding combined with solid food supplementation reduces clinical malnutrition by $70 \%$ (Cousens et al. 1993). The risk of stunting is reduced when solid food intake is supplemented by breastfeeding ( $\mathrm{AOR}=0.47$; IC[0.25; 0.87]) (Cousens et al. 1993). In contrast, children who are breastfed for less than one year have a significantly increased risk of stunting (AOR=2,2) (Teshome et al. 2009). However, longer breastfeeding can affect food consumption by disrupting appetite. Some children refuse to eat food and prefer to cling to mother's breast (Madise et Mpoma 1997).

\section{Data source and type of study}

These cross-sectional data are from the latest Burkina Faso Health and Demographic, Multiple Indicator Survey (EDS-MICS) conducted across all the country in 2010. In this secondary analysis, we use the subsample of the 6,994 under-five year old children who have undergone anthropometric measurements (INSD et ICF International 2012). Due to the complex sampling (two-stage stratified selection), the analysis took into account a weighting and structuring of the household selection in the calculation of estimates and confidence intervals. To this end, we used the "complex sample" procedure of SPSS software. 


\section{Analytical methods}

Cross-tabulation of independent and dependent variables helped select the independent variables to be entered into the multivariate model. The significance test for cross-tabulation with a categorical variable was the Chi-squared test or Fischer exact test and the crosstabulation with a continuous variable relied on the Student t-test. The entry of an independent variable into the multivariate model was based on a cross-tabulation p-value lower than 0.2. Given the dichotomy of the dependent variable, logistic regression was used to model the adjusted influence of feeding on stunting. The diagnostic elements of the model focused on the specification, adequacy, capture of cases affecting parameters and those with a strong influence on the adequacy of the model. Multi-collinearity was also tested to look for parsimony of factors and model convergence.

\section{RESULTS AND DISCUSSION \\ Description of population}

About one child out of eight (12.8\%) had a short mother. They were gender-equally distributed ( $51 \%$ of boys versus $49 \%$ of girls). Some children were considered as small by their mother at birth (14\%). The prevalence of diarrhoea was $15.3 \%$ in the last two weeks preceding the mother's interview. While half of the children had mothers without particular sex preference, the mother of one in ten children (11.2\%) would have liked to have more girls and that of a third (34.7\%) wants more boys (Results not presented).

For the child feeding, exclusive breastfeeding up to 6 months was practiced for only about one quarter of children (Table 1). The complementary food of 6-8-month olds still breastfed was inadequate in almost all cases (99.4\%). The trend was virtually the same for children aged 9-23 months (96.3\%). For non-breastfed children, less than one in ten received a diet that suited their needs. Overall, 7.2\% of children were adequately fed. It appears that boys were more often EBF than girls (27.6\% vs. 20.7\%). From 9 months onward, there were no significant differences between boys and girls, apart from breastfeeding. Overall, there was little significant difference in feeding by gender. Therefore, there was no gender discrimination in children's diets.

In Senegal also, it has been observed that there was no significant difference between boys and girls in the duration of breastfeeding (Simondon et Simondon 1998). Garenne (2003) reached to the same result with his study based on 39 demographic and health surveys conducted in subSaharan Africa, in which the average duration was 22.2 months for each sex, while the prevalence of stunting of boys was slightly but significantly higher than that of girls (30.2\% vs 28.9\%). The gender similarity in duration was also noted in New Zealand, in both aboriginal and European-descent populations (Horwood et Fergusson 1998).

However, some countries show a gender bias in feeding practice. In India, girls were breastfed less frequently, for shorter periods, and for a short length of duration than boys (Arokiasamy et Pradhan 2012). It is estimated that the average breastfeeding time of girls was $40 \%$ shorter and cessation of breast milk earlier (Barcellos, Carvalho, et Lleras-Muney 2012). In addition, they receive lower food quality (Angadi et Jawaregowda 2015). This explicit preference for the boy is underpinned by the wider opportunities for men to access better-paid employment and thus better benefits for their families and parents (Basu, Aundhakar, et Galgali 2014). 
Table 1: Adequacy of the child's diet by sex and breastfeeding status

\begin{tabular}{lcccrrr}
\hline Components of feeding & & & \multicolumn{3}{c}{ Gender of child } & P-value \\
& $\mathrm{N}$ & $\%$ & Male & Female & \\
\hline 0-5 mo. EBF & 769 & 24.1 & 27.6 & 20.7 & 0.027 \\
6-8 mo. breastfed & 363 & 0.6 & 0.0 & 1.2 & 0.155 \\
9-23 mo. breastfed & 1607 & 3.8 & 3.8 & 3.8 & 0.993 \\
6-23 mo. non-breastfed & 98 & 9.6 & 14.9 & 4.2 & 0.106 \\
24-59 mo. breastfed or not & 1271 & 3.4 & 3.4 & 3.4 & 0.988 \\
Adequate feeding* & 4108 & 7.4 & 8.0 & 6.7 & 0.161 \\
\hline
\end{tabular}

* An adequately fed child receives diets corresponding to his/her age and status of breastfeeding according to WHO/Unicef guidelines.

In Niger, boys are breast-fed for shorter periods because breastfeeding for long periods of time is often thought to make children less intelligent (Mousseau et Mittal 2006). Overall, out of 29 countries analysed worldwide, significant differences in IYCF by gender have been observed in Philippines, India and Kenya. It was only in the latter country that the proportion of girls bottle-fed was higher than that of boys (Arnold 1997).

The propensity to favour boys is not always nutritionally favourable to them. Tamashek boys in northern Mali received more non-breast milk; which led to more severe malnutrition (Mbacké et Legrand 1992). Boys may be bottle-fed more than girls, sometimes resulting in a better nutritional situation for girls (Barbieri 1991). In Nigeria, girls were more likely to be exclusively breastfed than boys (AOR-2,13; 95\% CI-[1.03-4.39]) (Agho et al. 2011). Condo et al. (2015) found that early feeding practices (early initiation of breastfeeding and six months of exclusive breastfeeding) favoured girls.

In Ethiopia, boys are three times more likely to receive complementary food on time than girls $(\mathrm{AOR}=2.9$; IC=[1.2-7.3]). This is certainly related to a gender culture that discriminates girls according to the belief that "a girl eats little and speaks little" (Semahegn, Tesfaye, et Bogale 2014). In the Gaza Strip, the introduction of food is similar for girls and boys with the exception of dairy products that are given earlier to boys (AOR=1.926; CI=[1.014-3.657]) (Sellen 2001).

\section{Prevalence of stunting associated with certain characteristics} Stunting prevalence of boys was significantly higher (37.7\% vs. 32.6\%) (Table 2). Overall, variations of stunting according to factors studied are consistent with expected trends. Better maternal education, greater maternal height, better maternal nutritional status, lower rank in polygamy, larger child size at birth, medical assistance at birth, better child feeding, and better household living standards are correlated with lower rates of child stunting. Children from animist mothers were more affected than those from Christian mothers.

The cross-tabulations with selected cofactors also generally conform with the expected trends. Height, BMI and age of the mother at child's birth reflect the biological and genetic endowment to the child.

In addition, as shown in Table 3, there is a significant increase in the risk of stunting with child age, as the consequence of the cumulative effect that becomes virtually irreversible beyond the age of two years (Waterlow 1994). A shorter birth interval is also linked to child stunting. Reduced birth interval is generally associated with maternal physiological and nutritional exhaustion that impedes gestational and neonatal growth and triggers malnutrition in children (Berg et Rotkirch 2014). There was no impact of number of siblings on risk of stunting 
Table 2 : Prevalence of child stunting according to child, mother and household sociodemographic characteristics $(n=6994)$

\begin{tabular}{|c|c|c|c|}
\hline Variable & Items & Stunting & P-value \\
\hline \multirow[t]{2}{*}{ Sex of child } & Male & 37,7 & \\
\hline & Female & 32,6 & 0,000 \\
\hline \multirow{3}{*}{$\begin{array}{l}\text { Education } \\
\text { level of mother }\end{array}$} & Illiterate & 37,8 & \\
\hline & Primary & 25,4 & \\
\hline & Secondary + & 13,3 & 0,000 \\
\hline \multirow[t]{3}{*}{ Religion } & Muslim & 35,9 & \\
\hline & Christian & 30,9 & \\
\hline & Animist & 43,0 & 0,000 \\
\hline \multirow{3}{*}{$\begin{array}{l}\text { Height of } \\
\text { mother }\end{array}$} & $<155 \mathrm{~cm}$ & 47,5 & \\
\hline & $155-165 \mathrm{~cm}$ & 37,0 & \\
\hline & $165 \mathrm{~cm}+$ & 26,0 & 0,000 \\
\hline \multirow{3}{*}{$\begin{array}{l}\text { Living } \\
\text { standard }\end{array}$} & Poor & 40,4 & \\
\hline & Middle & 35,7 & \\
\hline & Well-off & 19,0 & 0,000 \\
\hline \multirow{5}{*}{$\begin{array}{l}\text { Nutritional } \\
\text { status of } \\
\text { mother } \\
\text { Optimal IYCFa }\end{array}$} & Malnourished & 45,2 & \\
\hline & Normal & 35,0 & \\
\hline & Overweight & 21,2 & 0,000 \\
\hline & No & 38,0 & \\
\hline & Yes & 32,0 & 0,000 \\
\hline \multirow{4}{*}{$\begin{array}{l}\text { Polygamy } \\
\text { Rank }\end{array}$} & Not in union & 27,8 & \\
\hline & $1^{\text {st }}$ spouse & 36,7 & \\
\hline & $2^{\text {nd }}$ spouse + & 39,3 & \\
\hline & Monogamous & 33,2 & 0,000 \\
\hline \multirow[t]{7}{*}{ Ethnic group } & Bobo/Dioula/Senufo & 33,6 & \\
\hline & Fulani/Tuareg & 42,4 & \\
\hline & Gurmache & 44,7 & \\
\hline & Gurunsi & 26,8 & \\
\hline & Lobi/Dagari & 41,1 & \\
\hline & Mossi/Bissa & 33,7 & \\
\hline & Other & 27,1 & 0,000 \\
\hline \multirow[t]{3}{*}{ Size at birth ${ }^{\mathbf{b}}$} & Large & 29,9 & \\
\hline & Medium & 36,8 & \\
\hline & Small & 40,6 & 0,000 \\
\hline \multirow{2}{*}{$\begin{array}{l}\text { Assistance at } \\
\text { birth }\end{array}$} & Yes & 25,3 & \\
\hline & No & 38,2 & 0,000 \\
\hline
\end{tabular}

a : IYFC=infant and young child feeding

b: based on mother's perception 
Table 3 : Mean values of selected continuous determinants for stunted versus normal children under five $(\mathrm{n}=6994)$

\begin{tabular}{lrcc}
\hline Variables & $\begin{array}{r}\text { Normal } \\
\text { status }\end{array}$ & Stunting & Total sample \\
\hline Age of child $^{\mathbf{a}}$ & $26.93 \pm$ & $31.34 \pm 0.31$ & $28.48 \pm 0.18$ \\
& 0.27 & & $39.77 \pm 0.33$ \\
Birth interval $^{\mathbf{a}}$ & $\begin{array}{r}4.03 \pm \\
0.41\end{array}$ & $37.44 \pm 0.44$ & $3.58 \pm 0.04$ \\
$\begin{array}{l}\text { Number of } \\
\text { siblings }\end{array}$ & $3.57 \pm 0.04$ & $3.6 \pm 0.05$ & \\
\hline
\end{tabular}

${ }^{\mathrm{a}}$ Significant at $\mathrm{p}<5 \%$

\section{Logistic regression of stunting}

The multi-collinearity test of the factors included in the model using the VIF test resulted in values at most equal to 3, well below the recommended cut-off point of 10 . As a result, no variables were excluded from the model because of collinearity. Other diagnostic approaches to the model led to the exclusion of 20 cases that had an unduly strong influence on the residuals, on the estimated parameters and on the adequacy of the model. The limited number of cases concerned therefore does not affect the sample representativeness.

Adjusting with other independent variables included in the logistic regression model (Table 4), child stunting increases steadily with age between birth to 23 months and then follows a slight reduction beyond age 2 years. Twin births increase the risk of stunting. On the other hand, assisted delivery, a taller mother, Gurunsi ethnic group, older mother at child's birth, better living standard, higher maternal BMI, higher level of mother's education and larger perceived size at birth each contribute independently to a significant reduction in the child's risk of stunting.

Inadequate feeding induces three times risk of stunting in comparison balanced diet (Table 4). Young girls have a significantly lower adjusted risk of stunting (AOR=0.762). The interaction between child sex and diet indicates that the risk of stunting of malnourished boys is significantly higher compared to well-fed girls. The well-fed boy has a higher risk of stunting than a poorly fed girl (AOR=2.77). But, predicted probabilities based on this model (Table 5) indicate that there is no significant difference of stunting between boys and girls among wellnourished children.

Thus, the gap comes from children who receive a suboptimal diet. The probability of suffering from stunting is significantly higher for boys, adjusting for the various significant factors highlighted above. As a result, the effects of suboptimal diet on growth are more pronounced in male children, all other parameters being equal. Yet this is in a context of no gender discrimination in child feeding (Table 1).

For the succeeding reproductive birth interval, contrary to what might have been expected, it appears that an additional month leads to a significant increased risk of child stunting. This apparent paradox may be a mechanism implemented by mothers to adapt to their child poor nutritional status. To increase the chances of survival, mothers tend to prolong breastfeeding. This leads to delayed ovulation and a longer birth space. A similar result was highlighted in Senegal (Simondon et Simondon 1998). They found retrospectively that the prevalence of stunting at 9-10 months was 4 times higher among those whose breastfeeding cessation took place after 30 months than for those whose cessation happened after 18 months. The same was 
Table 4: Logistic regression of stunting of under-five year old children $(n=6994)$

\begin{tabular}{|c|c|c|c|}
\hline Variables & Items & $\begin{array}{l}\text { Odds } \\
\text { ratio }\end{array}$ & $\mathrm{P}$-value \\
\hline Age Group & $\begin{array}{l}0-5 \text { mo. } \\
6-8 \text { mo. } \\
9-23 \text { mo. } \\
24-59 \text { mo. }\end{array}$ & $\begin{array}{l}1 \\
1.157 \\
3.518 \\
3.176 \\
\end{array}$ & $\begin{array}{l}0.525 \\
0.000 \\
0.000 \\
\end{array}$ \\
\hline $\begin{array}{l}\text { Adequate } \\
\text { Feeding }\end{array}$ & $\begin{array}{l}\text { No } \\
\text { Yes }\end{array}$ & $\begin{array}{l}1 \\
0.337\end{array}$ & 0.002 \\
\hline $\begin{array}{l}\text { Assisted } \\
\text { delivery }\end{array}$ & $\begin{array}{l}\text { Yes } \\
\text { No }\end{array}$ & $\begin{array}{l}1 \\
1.551 \\
\end{array}$ & 0.000 \\
\hline $\begin{array}{l}\text { Height of } \\
\text { mother }\end{array}$ & $\begin{array}{l}<155 \mathrm{~cm} \\
155-165 \mathrm{~cm} \\
165 \mathrm{~cm}^{+} \\
\end{array}$ & $\begin{array}{l}1 \\
0.688 \\
0.402 \\
\end{array}$ & $\begin{array}{l}0.004 \\
0.000\end{array}$ \\
\hline $\begin{array}{l}\text { Main ethnic } \\
\text { groups }\end{array}$ & $\begin{array}{l}\text { Bobo/Diula/Senufo } \\
\text { Fulani/Tuareg } \\
\text { Gurmache } \\
\text { Gurunsi } \\
\text { Lobi/Dagari } \\
\text { Mossi/Bissa } \\
\text { Other }\end{array}$ & $\begin{array}{l}1 \\
0.734 \\
0.788 \\
0.556 \\
1.107 \\
0.721 \\
0.608\end{array}$ & $\begin{array}{l}0.095 \\
0.232 \\
0.007 \\
0.671 \\
0.027 \\
0.036\end{array}$ \\
\hline Age of mother at birth & $\begin{array}{l}\text { Years at child's } \\
\text { birth }\end{array}$ & 0.976 & 0.000 \\
\hline $\begin{array}{l}\text { Living } \\
\text { standard }\end{array}$ & $\begin{array}{l}\text { Poor } \\
\text { Middle class } \\
\text { Well-off } \\
\end{array}$ & $\begin{array}{l}1 \\
0.953 \\
0.510 \\
\end{array}$ & $\begin{array}{l}0.627 \\
0.000 \\
\end{array}$ \\
\hline $\begin{array}{l}\text { Nutritional } \\
\text { status of } \\
\text { mother }\end{array}$ & $\begin{array}{l}\text { Malnourished } \\
\text { Normal } \\
\text { Overweight/obesity }\end{array}$ & $\begin{array}{l}1 \\
0.647 \\
0.607 \\
\end{array}$ & $\begin{array}{l}0.000 \\
0.016\end{array}$ \\
\hline Birth interval & Months & 1.024 & 0.001 \\
\hline Education level & Attained level & 0.656 & 0.000 \\
\hline Size at birth & $\begin{array}{l}\text { Large } \\
\text { Medium } \\
\text { Small } \\
\end{array}$ & $\begin{array}{l}1 \\
1.254 \\
1.558 \\
\end{array}$ & $\begin{array}{l}0.026 \\
0.002\end{array}$ \\
\hline Twins & Status & 1.825 & 0.000 \\
\hline Sex of child & $\begin{array}{l}\text { Male } \\
\text { Female }\end{array}$ & $\begin{array}{l}1 \\
0.762\end{array}$ & 0.001 \\
\hline Optimal IYCF*Sex & $\begin{array}{l}\text { no*female } \\
\text { yes*male }\end{array}$ & $\begin{array}{l}1 \\
2.777\end{array}$ & 0.031 \\
\hline
\end{tabular}

${ }^{a}$ An adequately fed child receives diets corresponding to his/her age and status of breastfeeding according to WHO/Unicef guidelines.

IYCF=infant and young child feeding

true in Malawi (Madise et Mpoma 1997). Because of this paradox, meta-analyses were not able to establish a clear association between breastfeeding up to 2 years and stunting (Delgado et Matijasevich 2013). Surprisingly, Cousens et al. (1993) noticed a positive association between breastfeeding duration and nutritional status. They have shown that mothers of malnourished children, particularly those suffering from diarrhoea, stop giving breast-milk to their babies, considering that it aggravates their morbidity, whereas healthy children continued to be breastfed. For Marquis et al. (1997), the nature of relationship between breastfeeding and child 
Table 5: Predicted probability of child stunting according to feeding quality and gender

\begin{tabular}{lccc}
\hline Sex & Adequate feeding & Inadequate feeding & All \\
\hline Boy & $0.169[0.078-0.260]$ & $0.377[0.349-0.407]$ & $0.359[0.330-0.388]$ \\
Girl & $0.134[0.059-0.210]$ & $0.315[0.286-0.344]$ & $0.299[0.272-0.326]$ \\
All & $0.151[0.069-0.234]$ & $0.346[0.322-0.370]$ & $0.329[0.307-0.351]$ \\
\hline
\end{tabular}

growth depends not only on diarrhoeal episodes, but also on sufficiency of complementary food. The association is negative when health and complementary food are low. However, the link is not necessarily positive with high complementary food intake. For more consistent relationship, it is necessary to take the quality of diet into account through nutrient components, such as proteins. Their overall point is that the link between breastfeeding duration and nutritional status is an example of reverse causation-breastfeeding duration is increased by mothers because of their perception that a child is small or sickly.

It also appears that multiple birth pregnancy and size at birth variables are simultaneously significant. One's significance does not exclude the other's. The nutritional consequences of multiple birth therefore do not arise exclusively from the only weakness of birth weight, otherwise these two effects would have overlapped. The implications in terms of inflammation, physiological immaturity of essential organs such as the immune, cerebral, respiratory systems place the twins in a situation of health vulnerability that trigger the onset of height faltering (Falkner, Holzgreve, et Schloo 1994).

This study is subject to some limitations. Feeding data collected as part of the 2010 EDSBF used the 24-hour recall approach. This has led to the adoption of WHO/Unicef synthesis method. It was therefore not possible to apply that of Arimond and Ruel, which is based on a reference period of the last 7 days and which would certainly have brought more consistency in the measurement of children's feeding habits (Arimond et Ruel 2004). The longer is the reference period, the more reliable are the results of feeding habits. Also, the dataset does not capture information on the quantity of food consumed to assess its sufficiency. A complementary technique called "multiple-passage" that combines quantitative and qualitative aspects has been developed to surmount these data collection weaknesses. It is composed by 5 stages, including information on the timing, type of meal, quantity, type of product, etc. (Collège des Enseignants de Nutrition 2010). Nevertheless, its main disadvantages are the higher cost of collection and the data management skills required.

The analysis of stunting has generally focused on biological, behavioural and socio-cultural mechanisms. The differentiated effects of inadequate feeding on stunting experienced by boys suggest the involvement of biological factors rather than cultural or behavioural aspects (Garenne et Lafon 1998). For Marcoux (2002), the fact that both sexes receive equivalent nutritional mothering clearly showcases that girls are more resilient. For Mbacke and Legrand, girls' resilience is mainly active under conditions of scarcity (Mbacké et Legrand 1992). In fact, in a similar situation, boys may be more sensitive to a quantitative and qualitative variation in food intake.

However, the role of social and behavioural factors should not be overlooked, especially in the area of diet. Our findings clearly indicate that inadequate food intake is a favourable substrate for expression of stunting and especially, gender biased health degradation. The discriminating effect of long periods of suboptimal diet is highlighted by Almond et al. based on an in-depth analysis of the consequences of the 1959-60 China famine (Almond et al. 2007). They noticed a double deficit of male children recorded both on those born during the food crisis, and also 
on the next generation. Another overwhelming example is the consequences induced by the sieges of Leningrad and Netherlands during World War II. It caused an acute famine that brought a greater decrease in birth weight in male than in female children (Stinson 1985). This result complements the findings of Condo et al. (2015) who also found almost the same diets consumed by both sexes of HIV-exposed children, but with a worse height growth for boys.

On the other hand, in England and Wales during the 19th and 20th century, overall improvements in living conditions in general and access to better quality food led to a greater increase in boys' height (Harris 2009). Stinson (1985) came to the conclusion that under hostile conditions, males' growth falters more than that of females, but when the situation improves, the time needed for catch-up is shorter in males. But small improvements have a more perceptible impact on female growth, and with greater changes, males show better height growth improvement and full recovery from the effects of constraints (Stinson 1985). But, with the environment improvement, if mortality decreases in general, boys remain increasingly vulnerable to environmental stress (Wells 2000).

There are several possible biological explanations for male over-sensitivity to stunting (Díez Navarro 2018). Here we point out specifically, the interaction between hormonal and immune systems that is considered as a pillar for female resilience (Wondimagegn 2014). It has been established that men and women do not activate the components of the immune systems in the same way. Women use Th2 lymphocytes more, while men rely on Th1 lymphocytes. The fact that sex hormones can regulate Th1/Th2 balance may explain the difference in mortality between sex and age for infectious diseases (Muenchhoff et Goulder 2014). This mechanism also plays a role in the bioavailability of minerals, especially zinc. The focus on zinc lies in that its deficiency is a global public health problem that affects about 2 billion people. And stunting is a consequence of its deficiency. According to Unicef, a stunting prevalence higher than $30 \%$ in a community suggests a risk for zinc deficiency. (Prasad 1998) found that zinc supplementation affects the balance of Th1 and Th2 response. Mild zinc deficiency leaves the Th2 response intact but lowers the Th1 response. Therefore, a poor zinc diet would have a low Th1 response and would thus affect boys more. Zinc supplementation, on the other hand, might lead to a higher rate of female height growth (Garenne et al. 2007).

To eliminate this gender gap, the window of 1000-day opportunity from conception through the first two years of a child's life should be targeted (Ruel et Alderman 2013). Nutrition quality during pregnancy followed by rigorous compliance with infant and young child nutrition in the early years would certainly help break the intergenerational cycle of stunting (Remans et al. 2011). To this end, the country has already elaborated a national plan for scaling-up IYCN, which aims by 2025 to achieve $80 \%$ exclusive breastfeeding to 6 months and 30\% minimum acceptable diet rate at 6-23 months. This ambitious goal deserves efforts that are far greater than those being deployed so far.

\section{CONCLUSIONS}

The higher prevalence of child stunting found in nutritional surveys in Burkina Faso has not been thoroughly analysed previously. Even though the country has recently taken some firm commitments to combat its high level of child stunting, this issue has unfortunately been mentioned neither in a policy paper, nor in reflections on how to address the issue. With such a significant gender difference in nutritional stunting, we can obviously expect that addressing this gap will contribute to the reduction of the overall stunting prevalence. The contribution of this study is to raise awareness on the considerable role of food quality in reducing stunting 
prevalence, and also the gender gap. Unfortunately, the child food quality is far from being acceptable as shown by a nation-wide analysis (Dembele et Sanni 2020). Many opportunities exist to solve this, but the main challenge remains to scale up the implementation of actions for which knowledge and evidence already are well-established. The main constraint is that stakeholders' interventions are mostly oriented towards the time-limited acute malnutrition crisis, instead of the long-term integrated programming approach that child stunting reduction requires. Combatting stunting will contribute to the overall process of development, which in turn will reduce acute malnutrition.

\section{Conflict of interest}

The authors declare no conflict of interest.

\section{REFERENCES}

Agho, Kingsley E, Michael J Dibley, Justice I Odiase, et Sunday M Ogbonmwan. 2011.

« Determinants of Exclusive Breastfeeding in Nigeria ». BMC Pregnancy and Childbirth 11

(1): 2. https://doi.org/10.1186/1471-2393-11-2.

Almond, Douglas, Lena Edlund, Hongbin Li, et Junsen Zhang. 2007. « Long-term effects of the 1959-1961 China famine: Mainland China and Hong Kong ». Nber Working Paper Series 13384: 39.

Angadi, Mahabaleshwar, et Shashank Jawaregowda. 2015. « Gender discrimination in relation to breast feeding practices in rural areas of Bijapur district, Karnataka ». International Journal of Contemporary Pediatrics 2 (4): 340-44. https://doi.org/10.18203/2349-3291.ijcp20150970.

Arimond, Mary, et Marie T. Ruel. 2004. « Dietary Diversity Is Associated with Child Nutritional Status: Evidence from 11 Demographic and Health Surveys ». The Journal of Nutrition 134 (10): 2579-85.

Arnold, Fred. 1997. « Gender Preference for Children ». Comparative studies 23. Calverton, Maryland, USA: Macro-International. http://dhsprogram.com/publications/publication-FR270-DHS-Final-Reports.cfm.

Arokiasamy, P., et J. Pradhan. 2012. " Gender Bias Against Female Children in India ». https://doi.org/10.13140/RG.2.1.1719.0883.

Barbieri, Magali. 1991. Les déterminants de la mortalité des enfants dans le tiers-monde. Paris: Centre français sur la population et la développement.

Barcellos, Silvia, Leandro Carvalho, et Adriana Lleras-Muney. 2012. « Child Gender And Parental Investments In India: Are Boys And Girls Treated Differently? » w17781. Cambridge, MA: National Bureau of Economic Research. http://www.nber.org/papers/w17781.pdf.

Basu, Sangeeta, C.D. Aundhakar, et Amit Galgali. 2014. « Gender Discrimination in Relation to Exclusive Breast Feeding Practices amongst Twins in Rural India ». International Journal of Health Sciences and Research 4 (5): 139-43.

Berg, Venla, et Anna Rotkirch. 2014. «Faster Transition to the Second Child in Late 20th Century Finland: A Study of Birth Intervals ». Finnish Yearbook of Population Research XLIX: 73-86.

Bershteyn, Anna, Hil M Lyons, Dhileep Sivam, et Nathan P Myhrvold. 2015. « Association between Economic Growth and Early Childhood Nutrition ». The Lancet Global Health 3 (2): e79-80. https://doi.org/10.1016/S2214-109X(14)70382-1. 
Calkins, Kara, et Sherin U. Devaskar. 2011. « Fetal Origins of Adult Disease ». Current Problems in Pediatric and Adolescent Health Care 41 (6): 158-76. https://doi.org/10.1016/j.cppeds.2011.01.001.

Caulfield, Laura E., Stephanie A. Richard, Juan A. Rivera, Philip Musgrove, et Robert E. Black. 2006. « Stunting, Wasting, and Micronutrient Deficiency Disorders ». In Disease Control Priorities in Developing Countries, édité par Dean T. Jamison, Joel G. Breman, Anthony R. Measham, George Alleyne, Mariam Claeson, David B. Evans, Prabhat Jha, Anne Mills, et Philip Musgrove, 2nd éd. Washington (DC): World Bank. http://www.ncbi.nlm.nih.gov/books/NBK11761/.

Chang, S.M., S.P. Walker, S. Grantham-McGregor, et C.A. Powell. 2002. « Early Childhood Stunting and Later Behaviour and School Achievement ». Journal of Child Psychology and Psychiatry 43 (6): 775-83. https://doi.org/10.1111/1469-7610.00088.

Collège des Enseignants de Nutrition. 2010. « Méthodologie des enquêtes alimentaires: Support de Cours ». Université Médicale Virtuelle Francophone. http://campus.cerimes.fr/nutrition/enseignement/nutrition_14/site/html/cours.pdf.

Condo, Jeanine U., Anastasia Gage, Nancy Mock, Janet Rice, et Ted Greiner. 2015. « Sex Differences in Nutritional Status of HIV-Exposed Children in Rwanda: A Longitudinal Study ». Tropical Medicine \& International Health 20 (1): 17-23. https://doi.org/10.1111/tmi.12406.

Cousens, S., B. Nacro, V. Curtis, B. Kanki, F. Tall, E. Traore, I. Diallo, et T. Mertens. 1993. « Prolonged breast-feeding: no association with increased risk of clinical malnutrition in young children in Burkina Faso ». Bulletin of the World Health Organization 71 (6): 713-22.

Delgado, Carlos, et Alicia Matijasevich. 2013. « Breastfeeding up to Two Years of Age or beyond and Its Influence on Child Growth and Development: A Systematic Review ». Cadernos de Saúde Pública 29 (2): 243-56. https://doi.org/10.1590/S0102311X2013000200012.

Dembele, Bernard, et Mouftaou Amadou Sanni. 2020. « Inadequate Feeding Practices Persist in Burkina Faso ». American Journal of Food and Nutrition 8 (1): 16-22. https://doi.org/10.12691/ajfn-8-1-4.

Dewey, Kathryn G., et Khadija Begum. 2011. « Long-Term Consequences of Stunting in Early Life: Long-Term Consequences of Stunting ». Maternal \& Child Nutrition 7 (octobre): 5-18. https://doi.org/10.1111/j.1740-8709.2011.00349.x.

Díez Navarro, Andrea. 2018. « Ecoestabilidad femenina y malnutrición severa infantil: Evidencia a partir de intervenciones de ayuda humanitaria de Acción Contra el Hambre en países africanos, asiáticos y latinoamericanos ». Nutricion Clinica y Dietetica Hospitalaria, $\mathrm{n}^{0}$ 4: 127-34. https://doi.org/10.12873/374dnavarro.

DN, et Unicef. 2009. « Enquête nutritionnelle nationale du Burkina Faso 2009 ». Rapport d’enquête. Ouagadougou, Burkina Faso: Direction de la Nutrition, Unicef. . 2014. «Enquête nutritionnelle nationale du Burkina Faso 2014 ». Rapport d’enquête. Ouagadougou, Burkina Faso: Direction de la Nutrition, Unicef.

Falkner, F., W. Holzgreve, et R.H. Schloo. 1994. « Prenatal Influences on Postnatal Growth: Overview and Pointers for Needed Research ». In Causes and Mechanisms of Linear Growth Retardation (Stunting), par J. C. Waterlow.

Filmer, Deon, et Lant Pritchett. 1998. « Estimating Wealth Effects without Expenditure Data - or Tears: An Application to Educational Enrollments in States of India ». Policy Research Working Paper 1994. Washington, DC: The World Bank.

Forouzanfar, Mohammad H, Ashkan Afshin, Lily T Alexander, H Ross Anderson, Zulfiqar A Bhutta, Stan Biryukov, Michael Brauer, et al. 2016. « Global, Regional, and National Comparative Risk Assessment of 79 Behavioural, Environmental and Occupational, 
and Metabolic Risks or Clusters of Risks, 1990-2015: A Systematic Analysis for the Global Burden of Disease Study 2015 ». The Lancet 388 (10053): 1659-1724. https://doi.org/10.1016/S0140-6736(16)31679-8.

Garenne, Michel. 2003. "Sex differences in health indicators among children in African DHS surveys ». Journal of Biosocial Science 35 (4): 601-14. https://doi.org/10.1017/S0021932003006047.

Garenne, Michel, Heiko Becher, Yasome Ye, Bokar Kouyate, et Olaf Müller. 2007. « SexSpecific Responses to Zinc Supplementation in Nouna, Burkina Faso ». Journal of Pediatric Gastroenterology and Nutrition 44 (5): 619-28. https://doi.org/10.1097/MPG.0b013e31802c695e.

Garenne, Michel, et Monique Lafon. 1998. « Sexist diseases ». Perspectives in Biology and Medecine 41 (2): 176-89.

Harris, B. 2009. « Anthropometric history, gender and the measurement of well-being ». In Gender and wellbeing in Europe: Historical and contemporary perspectives, édité par B Harris, L Galvez, et H Machado, 59-83. Farham: Ashgate.

Heltberg, Rasmus. 2009. " Malnutrition, Poverty, and Economic Growth ». Health Economics 18 (S1): S77-88. https://doi.org/10.1002/hec.1462.

Horwood, L. John, et David M. Fergusson. 1998. « Breastfeeding and Later Cognitive and Academic Outcomes ». Pediatrics 101 (1): e9.

INSD, et ICF International. 2012. Enquête Démographique et de Santé et à Indicateurs Multiples du Burkina Faso (EDS-MICS-IV) 2010, Rapport définitif. Calverton, Maryland, USA: ICF International. http://www.measuredhs.com.

Madise, Nyovani Janet, et Mabel Mpoma. 1997. « Child malnutrition and feeding practices in Malawi ». Food and Nutrition Bulletin 18 (2): 190-201.

Marcoux, Alain. 2002. « Sex differentials in under-nutrition: A look at survey evidence ». Population and Development Review 28 (2): 275-84.

Marquis, Grace, Jean-Pierre Habicht, Claudio Lanata, Robert Black, et Kathleen Rasmussen. 1997. " Association of Breastfeeding and Stunting in Peruvian Toddlers: An Example of Reverse Causality ». International Journal of Epidemiology 26 (2):349-356.

Mbacké, Cheikh S.M., et Thomas K. Legrand. 1992. « Différences de mortalité selon le sexe et utilisation des services de santé au Mali ». Cahiers québécois de démographie 21 (1): 99. https://doi.org/10.7202/010106ar.

Mousseau, F., et A. Mittal. 2006. « Sahel: A Prisoner of Starvation? A Case Study of the 2005 Food Crisis in Niger ». The Oakland Institute.

https://www.oaklandinstitute.org/sites/oaklandinstitute.org/files/sahel_0.pdf.

Muenchhoff, M., et P. J. R. Goulder. 2014. «Sex Differences in Pediatric Infectious Diseases ». Journal of Infectious Diseases 209 (suppl 3): S120-26. https://doi.org/10.1093/infdis/jiu232.

Ndiku, M, K Jaceldo-Siegl, P Singh, et J Sabaté. 2011. « Gender inequality in food intake and nutritional status of children under 5 years old in rural Eastern Kenya ». European Journal of Clinical Nutrition 65 (1): 26-31. https://doi.org/10.1038/ejcn.2010.197.

OMS, éd. 1995. Utilisation et interprétation de l'anthropométrie: Rapport d'un comité d'experts OMS. Série de rapports techniques 854. Genève.

OMS, UNICEF, USAID, AED, UCDAVIS, et IFPRI. 2011. Indicateurs Pour Évaluer Les Pratiques D'alimentation Du Nourrisson et Du Jeune Enfant Partie 2 : Calculs. Vol. 2. 3 vol. Genève: World Health Organization. http://www.who.int/nutrition/publications/infantfeeding/9789241599757/en/.

Prasad, A S. 1998. «Zinc and immunity ». Mol Cell Biochem, n 188: 63-69.

Remans, R., P. M. Pronyk, J. C. Fanzo, J. Chen, C. A. Palm, B. Nemser, M. Muniz, et al. 2011. « Multisector Intervention to Accelerate Reductions in Child Stunting: An 
Observational Study from 9 Sub-Saharan African Countries ». American Journal of Clinical Nutrition 94 (6): 1632-42. https://doi.org/10.3945/ajcn.111.020099.

Ruel, Marie T, et Harold Alderman. 2013. « Nutrition-Sensitive Interventions and Programmes: How Can They Help to Accelerate Progress in Improving Maternal and Child Nutrition? » The Lancet 382 (9891): 536-51. https://doi.org/10.1016/S01406736(13)60843-0.

Sellen, D. W. 2001. « Weaning, Complementary Feeding, and Maternal Decision Making in a Rural East African Pastoral Population ». Journal of Human Lactation: Official Journal of International Lactation Consultant Association 17 (3): 233-44.

Semahegn, Agumasie, Gezahegn Tesfaye, et Alemayehu Bogale. 2014. « Complementary Feeding Practice of Mothers and Associated Factors in Hiwot Fana Specialized Hospital, Eastern Ethiopia ». Pan African Medical Journal 18. https://doi.org/10.11604/pamj.2014.18.143.3496.

Simondon, Kirsten B, et Francois Simondon. 1998. « Mothers Prolong Breastfeeding of Undernourished Children in Rural Senegal ». International Journal of Epidemiology 27 (3): 490-94. https://doi.org/10.1093/ije/27.3.490.

Stinson, Sara. 1985. "Sex Differences in Environmental Sensitivity during Growth and Development ». American Journal of Physical Anthropology 28 (S6): 123-47. https://doi.org/10.1002/ajpa.1330280507.

Teshome, Beka, Wambui Kogi-Makau, Zewditu Getahun, et Girum Taye. 2009. « Magnitude and determinants of stunting in children underfive years of age in food surplus region of Ethiopia: The case of West Gojam Zone ». Ethiopian Journal of Health Development. 23 (2): 98-106.

Walker, S. P., S. M. Chang, M. Vera-Hernandez, et S. Grantham-McGregor. 2011. « Early Childhood Stimulation Benefits Adult Competence and Reduces Violent Behavior ». PEDIATRICS 127 (5): 849-57. https://doi.org/10.1542/peds.2010-2231.

Walker, Susan P., Susan M. Chang, Christine A. Powell, Emily Simonoff, et Sally M. Grantham-McGregor. 2007. « Early Childhood Stunting Is Associated with Poor Psychological Functioning in Late Adolescence and Effects Are Reduced by Psychosocial Stimulation ». The Journal of Nutrition 137 (11): 2464-69.

Wamani, Henry, Anne Åstrøm, Stefan Peterson, James K Tumwine, et Thorkild Tylleskär. 2007. " Boys are more stunted than girls in Sub-Saharan Africa: a meta-analysis of 16 demographic and health surveys ». BMC Pediatrics 7 (1): 17. https://doi.org/10.1186/1471-2431-7-17.

Waterlow, J. C. 1994. "Summary of causes and mechanisms of linear growth retardation ». European Journal of Clinical Nutrition 48: S75-89.

Wells, Jonathan C. K. 2000. « Natural Selection and Sex Di4erences in Morbidity and Mortality in Early Life ». Journal of theoritical Biology 202 (jtbi.1999.1044): 65-76.

WHO. 2003. Global Strategy for Infant and Young Child Feeding. Geneva, Switzerland. http://www.who.int/nutrition/publications/gs_infant_feeding_text_eng.pdf.

Wondimagegn, Zelalem Tafese. 2014. « Magnitude and Determinants of Stunting Among Children in Africa: A Systematic Review ». Current Research in Nutrition and Food Science Journal 2 (2): 88-93. https://doi.org/10.12944/CRNFSJ.2.2.05. 